DOI: $10.14451 / 1.171 .71$

\title{
МИРОВОЙ И ОТЕЧЕСТВЕННЫЙ ОПЫТ В РАЗВИТИИ РЫНКА МОЛОКА И МОЛОЧНЫХ ПРОДУКТОВ
}

\author{
(c) 2019 Сурай Наталья Михайловна
}

кандидат технических наук, доцент кафедры экономики и управления

Московский государственный университет технологий и управления имени К.Г. Разумовского (ПКУ) 109004, г. Москва, ул. Земляной вал, д. 73

E-mail: natalya.mixajlovna.1979@mail.ru

\section{(c) 2019 Носов Владимир Владимирович}

доктор экономических наук, профессор кафедры экономики и управления

Московский государственный университет технологий и управления имени К.Г. Разумовского (ПКУ) 109004, г. Москва, ул. Земляной вал, д. 73

\section{(c) 2019 Диброва Жанна Николаевна}

кандидат экономических наук, доцент, директор Департамента правового и кадрового обеспечения Московский государственный университет технологий и управления имени К.Г. Разумовского (ПКУ) 109004, г. Москва, ул. Земляной вал, д. 73

\section{(C) 2019 Бобков Александр Николаевич}

доктор философских наук, профессор кафедры экономики и управления

Московский государственный университет технологий и управления имени К.Г. Разумовского (ПКУ) 109004, г. Москва, ул. Земляной вал, д. 73

\section{(c) 2019 Айдинов Халин Тохтарович}

кандидат экономических наук, профессор кафедры экономики и управления Московский государственный университет технологий и управления имени К.Г. Разумовского (ПКУ) 109004, г. Москва, ул. Земляной вал, д. 73

В статье анализируется отечественный и мировой опыт производства и реализации молока и молочных продуктов. Уделено достаточное внимание выявлению недостатков и главным задачам, стоящим перед молочной отраслью в РФ, а также условиям смены экстенсивного пути развития молочного скотоводства на интенсивный путь.

Ключевые слова: рынок молока и молочной продукции, государственная поддержка, поголовье молочного стада, продуктивность молочного стада, Доктрины продовольственной безопасности Российской Федерации.

Молоко и молочные продукты являются одними из наиболее потребляемых пищевых продуктов как в мире, так и на территории Российской Федерации. В современном мире молоко рассматривается как уникальный и самый ценный источник белка, дефицит которого испытывают большинство стран мира. Потребность в белке с каждым годом увеличивается вместе с ростом населения земли и его благосостояния. Молоко служит сырьем для производства широкой группы продуктов питания, использующихся в различных подотраслях пищевой промышленности и фармацевтике, производстве непищевых продуктов.

Различия между рынками молочных продуктов разных стран мира, связаны с различиями в спросе населения этих стран на данные продукты. Уровень дохода, доступность молока и его цена являются основными факторами, определяющими различие уровней спроса на молочную продукцию в разных странах. Например, высокая стоимость транспортировки и предпочтения местного населения ограничивают развитие международного рынка для ферментированных молочных напитков и йогуртов.

Молоко и молочные продукты входят в перечень продукции Доктрины продовольственной безопасности Российской Федерации, а также они имеют первостепенное значение в рационе населения. Доля молочных продуктов в структуре продовольственной корзины в различных регионах составляет от 20 до 30\%. В ближайшие 
годы Россия станет одним из лидеров глобального агропромышленного комплекса, отметил президент Российской Федерации Владимир Владимирович Путин на Всероссийском форуме сельхозпроизводителей в городе Краснодаре.

Министр Минсельхоза Д. Патрушев подчеркивает, что «молочное животноводство обладает наибольшим потенциалом роста. Поддержка отрасли имеет стратегическое значение - ежегодно на эти цели государство направляет более 25 млрд. рублей. Это способствует проведению технологической модернизации предприятий, совершенствованию селекционно-племенной работы, развитию фермерских хозяйств, увеличению ассортимента отечественной молочной продукции и повышению ее качества». Стратегически необходимо, чтобы правительство России стимулировало развитие сырьевой базы страны в целях сокращения зависимости от внешней конъюнктуры цен.

В 2018 году на мировой рынок молока и молочной продукции негативно влияют следующие факторы: торговые войны между странами, неоднозначная ситуация со спросом в Китае, эмбарго в России и отмена квот в Евросоюзе, рост потребления растительных альтернатив, резкое сокращение европейского интервенционного фонда, более сбалансированные цены на жиры и белки. Данные факторы приводят к общему перепроизводству молока и низким ценам на уровне аграриев. Хотя на мировом рынке можно отметить положительные тенденции, которые выражаются в постоянном росте населения земли, растущих доходах жителей развивающихся стран, увеличении численности городского на- селения и потребительской моде на здоровое питание.

Мировое производство молока и продуктов на его основе с каждым годом увеличивается, однако темпы его роста не очень высоки. Причинами такого незначительного темпа роста являются естественные ограничения сырьевой базы, экономические трудности, а также неблагоприятные погодные условия, отмечаемые во многих странах мира в последние несколько лет. Ежегодно мировое производство прибавляет от 5\% до 7\%. По данным Международной молочной федерации (IDF) по итогам 2018 года, общий объем мирового производства молока всех видов составил 876 млн. тонн, в том числе коровьего молока -696 млн. тонн. Следовательно, в 2018 г. относительно уровня 2016 г. отмечается рост объема мирового производства молока на $7,2 \%$, составив, по оценкам, 876 млн. тонн, из них более $85 \%$ составляет коровье молоко (табл. 1). Ёмкость мирового рынка молока более 600 млн. тонн.

В настоящее время Россия - один из крупнейших в мире производителей молока и молочной продукции (табл. 2). Только за последние 3 года производство молока в промышленном секторе увеличилось на 1,3 млн.тонн. Согласно данным мирового рейтинга, подготовленного на основе материалов IFCN и RDRC (Центра изучения молочного рынка), Россия занимает 13 место в мире по поголовью дойного стада. В отрасли происходит интенсификация применения высокоэффективных технологий, совершенствование системы управления стадом, более полная реализация генетического потенциала

Таблица 1. Динамика производства молока в мире, млн. тонн

\begin{tabular}{|l|c|c|c|c|c|c|c|c|c|}
\hline & 1990 г. & 2000 г. & 2005 г. & 2009 г. & 2014 г. & 2015 г. & 2016 г. & 2017 г. & 2018 г. \\
\hline молоко всех видов & 477,6 & 580 & 645 & 703 & 801 & 808,7 & 817 & 849 & 876 \\
\hline в т.ч. коровье молоко & 406,0 & 489 & 541 & 587 & 661 & 671 & 674 & 696 & 727 \\
\hline
\end{tabular}

Таблица 2. Крупнейшие производители молока в мире за период 2016-2018 гг.

\begin{tabular}{|c|c|c|c|c|c|c|c|c|}
\hline \multirow{2}{*}{ Страны } & \multicolumn{2}{|c|}{ Объем производства молока, млн. тонн } & \multicolumn{3}{|c|}{ Поголовье дойного стада, млн. гол. } \\
\cline { 2 - 10 } & 1986 г. & 2016 г. & 2017 г. & 2018 г. & $\begin{array}{c}01.01 . \\
1986 \text { г. }\end{array}$ & $\begin{array}{c}01.01 . \\
2016 \text { г. }\end{array}$ & $\begin{array}{c}01.01 . \\
2017 \text { г. }\end{array}$ & $\begin{array}{c}01.01 . \\
2018 \text { г. }\end{array}$ \\
\hline ЕС-28 & - & 163,9 & 165,5 & 165,67 & - & 23,6 & 23,5 & 23,5 \\
\hline США & 65 & 92,3 & 97,7 & 98,8 & 17 & 9,3 & 9,38 & 9,4 \\
\hline Индия & - & 60 & 83,5 & 178,8 & - & 54,5 & 54,5 & 55 \\
\hline Китай & - & 35,7 & 35,5 & 40 & - & 8,0 & 8,7 & 8,9 \\
\hline Россия & 102,2 & 30,8 & 31,2 & 31,6 & 42,9 & 8,32 & 8,26 & 8,3 \\
\hline
\end{tabular}


молочного скота при сохранении господдержки. Первое место по поголовью дойного стада в мире занимает Индия, с учетом буйволиц поголовье в 2016 году насчитывало 131,3 млн. голов. Причем доля индийского поголовья в мире составляет 38,7\%. Второе место занимает Пакистан, где поголовье коров и буйволиц составило 21,6 млн. голов. В десятку лидеров по поголовью входят африканские страны, Бразилия, США, Турция и Афганистан.

Евросоюз является самым крупным регионом-производителем молока в мире. Так, по итогам 2017 года совокупный объем молока, производимого ЕС-28, составил 165,45 млн. тонн, что занимает почти $24 \%$ от общемирового объема производства молока. При этом 94\% молока направляется на переработку. Ключевыми молокопереработчиками являются такие компании как Lactalis, Danone, FrieslandCampina, ArlaFoods, DMK.

По данным Международный молочный исследовательский Центр IFCN следует отметить, что топ-20 крупнейших компаний мира по переработке молока потребляют 25,4\% мирового молока. Так, в 2017 году, лидеры рынка переработали 211 млн. тонн молока, что на 11 млн. тонн больше, чем в 2015 году. Первое место занимает корпорация Dairy Farmers of America, которая потребляет для переработки 3,5\% молока, производимого во всем мире. На втором месте новозеландская Fonterra. Третье место принадлежит французской группе Lactalis. Arla, Nestlé и FrieslandCampina вместе перерабатывают около 14 миллионов тонн молока. Индийский молочный гигант Amul - 9,3 млн. тонн. Две китайские молочные компании Yili Group и Mengniu вместе переработали 13,6 млн. тонн молока.

В мировой структуре производства молока США находятся на втором месте и занимают $19 \%$ рынка. Основная доля молока в США производится в Калифорнии, Висконсине, Нью-Йорке, Айдахо и Пенсильвании. По данным USDA, поголовье коров в США составляло 8,72 млн. голов в 2016 году, наибольшее число животных насчитывается в Калифорнии - 1,8 млн. голов. Объем произведенного молока превышает возможности внутреннего рынка, поэтому часть продукта США продают на внешние рынки. Основным импортером американских молочных продуктов является Мексика, большая часть товаров поставляется на азиатский рынок. США являются вторыми по величине в мире экспортерами молока и молочных продуктов, уступая в этом Евросоюзу.

Во времена Советского Союза в отечественном скотоводстве преобладало молочное направление в сочетании с мясо-молочным. Только 5\% от общего поголовья крупного рогатого скота составляли животные мясных пород, 50\% приходилось на молочные породы скота, и 45\% на комбинированные молочно-мясные породы. C 1986 года наблюдается сокращение поголовья молочного скота, и за этот период времени объем производства молока снизился на $40 \%$. Советское скотоводство развивалось по экстенсивному пути, который не требовал серьезных капитальных вложений, отличался слабой механизацией и автоматизацией производства, вследствие чего продуктивностью поголовья была на невысоком уровне.

Рост объемов валовых надоев осуществлялся за счет увеличения численности молочного стада страны. В смутное перестроечное и постперестроечное время крупные молочные комплексы и фермы с высокой степенью механизации фактически перестали функционировать, что не могло отрицательно повлиять на молочную отрасль. Доля отечественных фермерских хозяйств в общем производстве молока незначительная и составляет порядка 7,6\%. Поскольку фермерские хозяйства не выдерживают конкуренцию с крупными сельскохозяйственными предприятиями.

Минсельхоз РФ называет рынок КНР одним из главных направлений развития отечественного молочного экспорта. В настоящее время основными экспортными направлениями для России являются страны Таможенного союза и СНГ. В перспективе Россия планирует выйти в Китай, а также другие направления Юго-Восточной Азии.

Согласно приказу Минздрава России от 10.08.2016 г. № 614 «Об утверждении Рекомендаций по рациональным нормам потребления пищевых продуктов, отвечающих современным требованиям здорового питания», рациональная норма потребления молока и молокопродуктов (в пересчете на молоко) на человека в год составляет 325 кг. По методологии Доктрины продовольственной безопасности РФ, уровень самообеспечения в отношении молока и молокопродуктов (в пересчете на молоко) должен составлять не менее 90\%, а по итогам 2018 года составил 82,4\%. При этом показатель обеспеченности товарным молоком составляет 66\%. Важно 
отметить, что $60 \%$ отечественного товарного молока соответствует требованиям высшего сорта.

В молочной отрасли и взаимосвязанных с ней отраслях функционирует более 21 тысячи предприятий, в которых занято свыше 1,4 миллиона человек (примерно 2\% от всех занятых в России). При этом в России насчитывается более 20 тыс. производителей сырого молока, более 900 переработчиков, более 200 обслуживающих компаний. Продукция молочной отрасли составляет до $15 \%$ от оборота розничных сетей. В настоящее время перерабатывающие мощности молочной отрасли в России загружены на 60$70 \%$, то есть их дефицит не является ограничивающим фактором для производства.

По данным Национального союза производителей молока (далее «Союзмолоко») в 2018 году потребление молока и молокопродуктов составило 234 кг. на одного человека, что составляет $72 \%$ от нормы Минздрава. Например, уровень потребления молока и молочной продукции в пересчете на молоко в Новой Зеландии, по данным Международный молочный исследовательский Центр IFCN, в 2015 году составил 601 кг на душу населения. В странах ЕС потребление на душу населения составляет около 306 кг [2]. В настоящее время потребление молока в среднем по миру составляет 115 кг на человека, в странах с развитой экономикой - 230 кг., в странах с развивающейся экономикой -75 кг.

В настоящее время можно отметить главные задачи, стоящие перед молочной отраслью в РФ:

- увеличить объем производства молока-сырья, сохранив требуемый уровень качества;

- обеспечивать 90\% внутреннего потребления собственным производством;

- повысить конкурентоспособность отечественной молочной продукции на российском рынке.

Главные причины недостаточного производства сырого молока в России:

- низкая инвестиционная привлекательность молочного животноводства в большинстве регионов. В России высокий уровень процентных ставок по кредитам для сельскохозяйствен- ных предприятий. Рентабельность производства сырого молока в среднем по стране составляет $10 \%$;

- неэффективное распределение средств в рамках существующей программы государственной поддержки;

- низкий уровень компетенций среди всех групп работников, занятых производством молока;

- в отрасли не существует устоявшегося подхода к контролю качества используемых материалов (например, семя, корма), процесса разведения скота, качества производимого молока - в результате этого значительно затрудняется анализ эффективности отрасли, а также результатов использования выделяемых средств государственной поддержки;

- высокая волатильность цены российского сырого молока. Данный рынок дефицитный, с высокой долей инфляционных ресурсов в себестоимости;

- слабая конкурентная позиция по цене и качеству молокоемких продуктов (например, сыр, масло, сухая сыворотка). Высокая себестоимость производства отечественной молочной продукции формирует данный продукт неконкурентоспособным по сравнению с иностранными конкурентами;

- отсутствие данных, необходимых для качественного понимания ситуации в данной отрасли (низкий уровень информационной оснащенности сельского хозяйства);

- низкая инвестиционная привлекательность отрасли, непрозрачность и неудовлетворительное качество кадров.

В молочной отрасли можно отметить достаточно значительный срок окупаемости по сравнению с отраслями растениеводства и другими видами животноводства. Поскольку в отрасли наблюдаются длинный инвестиционный цикл, потребности в значительных суммах начальных инвестиций и низкая операционная эффективность производства.

В условиях дефицита и за счет естественной сезонности производства, а также из-за климатических особенностей, в отрасли наблюдается

Таблица 3. Динамика потребления молока и молокопродуктов на душу населения за 2014-2018 гг., кг.

\begin{tabular}{|c|c|c|c|c|c|c|}
\hline Наименование & Норма потребления & 2014 г. & 2015 г. & 2016 г. & 2017 г. & 2018 г. \\
\hline в мире & - & 110,7 & 111,3 & 111,5 & 113 & 115 \\
\hline РФ & 325 кг. & 244 & 239 & 236 & 233,4 & 234 \\
\hline США & 415 кг. & 262 & 269 & 270 & 276 & 276 \\
\hline
\end{tabular}


сильная волатильность по цене. Себестоимость производства молока в России выше, чем в других странах, за счет стоимости заемных средств, более высокой волатильности на рынке кормов, инфляционного давления других ресурсных составляющих, что негативным образом сказывается на себестоимости производства молокоемких товаров.

Объем производства товарного молока ключевой целевой индикатор развития молочного скотоводства и основной ресурс для молочной промышленности (табл. 4). Доля товарного молока в общем объеме производства составляет в России $-70 \%$, в США - $98 \%$.

В настоящее время основной вклад в позитивную динамику производства вносят сельскохозяйственные организации - производители со средним дойным поголовьем в 1000 и более голов (табл. 5). Однако на молочном рынке имеется дефицит в размере 7-8 млн. тонн молока для полного обеспечения показателя Доктрины продовольственной безопасности.

Для сохранения достигнутых результатов и продолжения развития реализуются меры госу- дарственной поддержки, направленные не только на развитие молочного животноводства, но и строительство, реконструкцию и модернизацию предприятий по переработке молока-сырья, что позволяет осуществлять полный цикл переработки от молока-сырья до готовой продукции. Важнейшим качественным показателем, характеризующим эффективность молочного поголовья, является продуктивность (табл. 6).

Американские молочные коровы - одни из самых продуктивных в мире. Так, по данным министерства сельского хозяйства США, средний надой на одну корову по итогам 2017 г. составил 10340 кг молока. Американские фермеры ставят скоту успокаивающую классическую музыку в доильных залах, запускают вентиляторы и пульверизаторы в целях имитации весеннего бриза, в то время как специальные механические установки обеспечивают коровам еще более приятные ощущения. Коровы по утрам в амбаре отдыхают на водяных кроватях с контролируемым температурным режимом и питаются диетическими блюдами, а высокотехнологичные бирки на ногах животных отслеживают

Таблица 4. Динамика валового производства молока в РФ (млн. тонн)

\begin{tabular}{|c|c|c|c|c|c|c|c|c|c|c|c|c|}
\hline & 1986 & 1990 & 1992 & 1995 & 1996 & 2000 & 2005 & 2010 & 2015 & 2016 & 2017 & 2018 \\
\hline Всего & 102,2 & 55,7 & 47,2 & 39,2 & 35,8 & 32,3 & 31,1 & 31,8 & 30,8 & 30,7 & 31,2 & 31,6 \\
\hline $\begin{array}{c}\text { товарное } \\
\text { молоко }\end{array}$ & - & 30 & 28 & 26 & 24 & 23 & 18,9 & 19 & 20,1 & 20,6 & 21,4 & 22,2 \\
\hline
\end{tabular}

Таблица 5. Основные показатели, характеризующие эффективность производства молока и молочной продукции по категориям хозяйств в РФ, 2018 г.

\begin{tabular}{|l|c|c|c|}
\hline \multirow{2}{*}{ Показатель } & \multicolumn{3}{|c|}{ Категория хозяйств } \\
\cline { 2 - 4 } & $\mathrm{CXО}$ & КФХ и ИП & ЛПХ \\
\hline Объем производства молока, млн.т. & 15,6 & 2,4 & 13,1 \\
\hline Объем производства товарного молока, млн.т. & 14,9 & 1,7 & 4,7 \\
\hline Поголовье молочных коров, млн. гол. & 3,31 & 1,28 & 3,71 \\
\hline Продуктивность одной коровы в год, кг. & 6241 & 3695 & 5838 \\
\hline Доля товарного молока в общем объеме производства,\% & 94 & 70 & 34 \\
\hline
\end{tabular}

Таблица 6. Средняя продуктивность производства молока в США и России, от одной коровы кг. в год (2016-2018 гг.)

\begin{tabular}{|c|c|c|c|}
\hline \multirow{2}{*}{ Страны } & \multicolumn{3}{|c|}{ Средняя производительность от одной коровы, кг. в год } \\
\cline { 2 - 4 } & 2016 г. & 2017 г. & 2018 г. \\
\hline США & 10159 & 10340 & 10340 \\
\hline Россия & 4218 & 4368 & 4390 \\
\hline
\end{tabular}


самочувствие. По расчетам фермеров, коровы должны лежать минимум 12 часов в день, что максимизирует их надои.

Исторически в СССР, производство молока характеризовалось экстенсивным и низко продуктивным направлением. С отказом от плановой экономики и появлением частных инвестиций в анализируемом секторе ситуация начала меняться в сторону большей индустриализации. В период с 1976 года по 2018 год средняя продуктивность поголовья выросла с 2,6 до 5,8 тонн молока на корову в год. Однако поголовье продолжало сокращаться, что привело к дальнейшему снижению объема производства молока с 102,2 до 31,6 млн. тонн в год.

На рост объемов производства молочной продукции отрицательно сказывается низкая товарность молока. Так, из общего объема произведенного в России молока за 2018 г. в переработку поступило $70 \%$. В странах европейского сообщества товарность молока составляет более 91\%. Из общего объема произведенного молока в количестве 156,1 млн. тонн на выработку продукции направлено 142,1 млн. тонн.

Развитию объемов выпуска молочной продукции в значительной степени мешает низкий уровень оснащения производств современным оборудованием. По оценке Минсельхоза России износ оборудования, находящегося в эксплуатации, составляет более 58\%. Активному переоснащению предприятий молочной отрасли мешает низкий уровень рентабельности, который для многих предприятий не превышает 7\% [3].

Можно выделить три ключевые проблемы рынка молочных продуктов в России. Первой следует отметить дефицит сырья (особенно качественного). Мощности имеющихся предприятий, а их количество более 2300 заводов различных объемов переработки, не превышают $60 \%$. Второй проблемой является сокращение платежеспособного спроса на качественные продукты, особенно сыры. Третьей проблемой, которая становится все более актуальной, является рост объемов производства заменителей натуральных продуктов (субститутов). Их качество и полезность вызывают у покупателей большие сомнения. Различные молокосодержащие продукты, особенно сырные продукты, творог, сметана воспринимаются потребителями как «эрзац- продукты» и психологически вызывают настороженность. Этому способствует достаточно большое количество фальсифицированной молочной продукции, присутствующей в торговле.

Качественные изменения возможны только при условии смены экстенсивного пути развития молочного скотоводства на интенсивный путь. Для этого, прежде всего, необходимо:

1) качественный подход к кормлению скота, активное применение аминокислот, витаминов, ферментов, микро- и макроэлементов и других биологически активных средств, которые успешно используются в странах с развитым молочным скотоводством;

2) техническое перевооружение предприятий молочного сектора;

3) налаживание эффективной племенной и селекционной работы в сфере воспроизводства молочного поголовья, основанной на достижениях мировой науки;

4) эффективное использование генетического потенциала скота (в настоящее время потенциал используется на 52\%), необходимо улучшение генетики скота за счет реализации генетического плана, повышение показателей по воспроизводству, повышение уровня здоровья стада, в частности, за счет балансирования рационов для КРС, создание максимально комфортных условий содержания и доения, а также интенсивной работы с персоналом в области обучения и повышения квалификации.

Наиболее эффективными мерами для сглаживания влияния фактора сезонности производственного процесса являются:

- улучшение качества ветеринарного обслуживания;

- нормированное кормление;

- применение современных методов искусственного оплодотворения скота;

- регулирование графиков отелов.

Государство - важнейший участник молочной отрасли. В Китае и Бразилии, государство видит задачей отрасли интенсивный рост производства молока, фермеры получают поддержку в виде ценового регулирования (потолок закупочной цены) и значительных компенсаций на капитальные затраты (приобретение скота и строительство ферм).

В Канаде, США, большинстве стран Евросоюза стоит проблема перепроизводства. Чтобы избежать падения внутренних цен и сохранить экономическую эффективность отрасли правительства используют набор ограничивающих мер (квоты, пол закупочной цены, лицензиро- 
вание производства сырого молока и др.). Кроме регулирования баланса производителей и переработчиков, государство играет важную роль в организации сквозных систем контроля качества - от ресурсов производства до самого молока. При этом непосредственный контроль качества на каждом из участков цепочки в большинстве стран осуществляется независимыми лабораториями.

В России современная история государственной поддержки молочной отрасли началась в 2006 году с введением государственных субсидий на выплату процентов по инвестиционным кредитам. К 2013 году набор мер поддержки дополнился субсидиями на килограмм реализованного молока первого и высшего сортов, поддержки племенного животноводства и региональных программ. Общий объем поддержки составил 32 млрд. руб. Использование товарных интервенций - закономерное расширение механизмов программы. В среднем субсидия на литр молока составляет 60-70 коп./л, но в некоторых регионах, например, в Ленинградской, Тюменской областях, она может составлять 2-3 руб./л.

В настоящее время условиями для получения субсидий являются развитие производства, ежегодное увеличение продуктивности и поголовья. Однако для предприятий, продуктивность которых составляет более 7 тыс. л на голову в год, существуют особые условия предоставления господдержки. Они могут получить субсидии, не представив прироста по продуктивности, а продемонстрировав ее небольшой спад - в несколько процентных пунктов. Таким предприятиям предоставляются самые высокие субсидии с повышающим коэффициентом.

Важным фактором инвестиционной привлекательности молочного животноводства является государственная поддержка. Для производителей сырого молока предусмотрена возможность получения несколько видов субсидий:

- субсидирование части процентной ставки по инвестиционным кредитам $(6,6 \%)$ или на поддержку инвестиционной привлекательности сектора - возмещение прямых понесенных затрат и льготные 5\%-ные инвестиционные кредиты;

- субсидирование части процентной ставки по краткосрочным кредитам (1,3\%);

- субсидии на возмещение части прямых понесенных затрат на создание и модернизацию объектов животноводческих комплексов молочного направления (молочных ферм) - 3,8\%

- субсидии на поддержку племенного крупного рогатого скота молочного направления $2,3 \%$;

- поддержка экономически значимых региональных программ в области молочного скотоводства;

- субсидии на 1 кг реализованного товарного молока (12,7\%);

- субсидии на возмещение части прямых понесенных затрат при создании молочных комплексов, поддержку развития племенного молочного скотоводства в рамках «единой» субсидии,

- гранты фермерам на развитие молочных ферм;

- на развитие генетической и племенной инфраструктуры - поддержка племенных хозяйств.

В 2017 году на поддержку животноводства выделено 226 млрд. рублей.

В России благодаря государственной поддержке развитие получило мясное скотоводство. По итогам 2017 года поголовье специализированного мясного и помесного крупного рогатого скота во всех категориях хозяйств составило 3,7 млн. голов. В структуре производства крупного рогатого скота доля специализированного мясного и помесного скота составила 16\%, в 2008 году было всего 2\%. Средний надой молока на 1 корову в сельхозорганизациях по итогам прошлого года составил 5700 кг.

В США молочные предприятия крупного размера занимают 20\% от всего количества ферм страны. Но их доля в общем производстве молока составляет 75\%. Поголовье самых крупных молочных предприятий в США составляет до 6 тысяч дойных коров, а средних - до 800.

Кроме того, страны, идущие по интенсивному пути развития молочного скотоводства, идут на коренное изменение породного состава молочного КРС: увеличивается численность поголовья таких пород, которые наилучшим образом соответствуют требованиям внутреннего и внешнего рынков по стоимости и качеству производимой продукции. Например, в молочном стаде Швейцарии, которая славится своими сырами и маслом, резко увеличилась численность шведской молочной породы, продукция которой отличается высокой жирностью. Большой объем производимого в Дании сливоч- 
ного масла вызвал увеличение поголовья красной датской породы и снижение численности шортгорнской, что тоже связано с содержанием в продукции этих пород молочного жира. Увеличение потребления на внутреннем рынке Великобритании свежего молока, причем нередко из удаленных от крупных городов хозяйств, привело к росту поголовья специализированных пород молочного скота (айрщирской, фризской и британской). Канадская специфика развития молочного скотоводства отличается высокой степенью организации селекционной и племенной работы, особыми методами экономического стимулирования фермерских хозяйств и наиболее рациональными системами содержания и кормления молочного скота. В результате Канада признана мировым лидером по экспорту скота племенных пород по продуктивности молочного скота.

В странах с развитой экономикой главный рычаг государственного влияния на молочное производство - это цена. Именно государство поддерживает минимальный уровень цен как на молоко, так и на молочные продукты. Например, в США цена закупки молока рассчитывается так, чтобы она покрывала производственные затраты, затраты на переработку и обеспечивала производителю заранее запланированный размер получаемой прибыли.

В Канаде действует похожая система, но в этой стране государство не только регулирует цены на рынке молока, но напрямую контролирует объем его производства через систему установленных квот.

В России в рыночных условиях сельское хозяйство постепенно возвращается к программно-целевому способу регулирования сельского хозяйства. В настоящий момент молочная отрасль животноводства рассматривается в качестве национального приоритета и поставлена задача вывести ее на уровень, который позволил бы России использовать ее в качестве конкурентного преимущества на рынках всего мира.

Резюмируя все вышесказанное, необходимо отметить, что молочная отрасль Российской Федерации в настоящее время находится в не самом лучшем состоянии, но имеется положительная динамика в области ее развития и переориентирования в соответствии с мировыми стандартами.

Основные мероприятия по развитию молока и молочной продукции в России:
- реализация мероприятий Дорожной карты по развитию отечественного племенного животноводства;

- совершенствование нормативной правовой базы в области племенного животноводства;

- повышение молочной продуктивности коров, в том числе посредством реализации генетического потенциала, обеспечения технологических условий (содержание, зоогигиена и т.д.);

- реализация мер по улучшению воспроизводства стада, увеличению охвата искусственным осеменением коров, содержащихся, в том числе в хозяйствах населения;

- проведение модернизации и реконструкции производственных мощностей для увеличения объемов производства животноводческой продукции;

- улучшение состояния кормовой базы, как обязательного условия для развития высокопродуктивного животноводства;

- разработка долгосрочной (не менее чем на 15 лет) стратегии развития молочной отрасли РФ с фиксированным комплексом инструментов регулирования и мер поддержки отрасли, выделение объемов поддержки молочной отрасли отдельными статьями федерального бюджета, доработка механизма консолидации субсидий для предоставления инвесторам гарантий оказания поддержки на весь период реализации инвестиционных проектов. Сохранение объема поддержки молочной отрасли на уровне не ниже, чем в 2016 году ( $\approx 26,8$ млрд. руб. за счет средств федерального бюджета).

- разработка и реализация комплекса мер немонетарного регулирования отрасли. Такими мерами должны стать: интервенции, технические регламенты, снижение административной нагрузки, в том числе отказ от электронной ветеринарной сертификации в отношении готовой продукции. Ужесточение ответственности (увеличение штрафов, конфискация оборудования) за нарушение технического регламента ЕАЭС в части маркировки молочной продукции, в частности за отсутствие на этикетке информации о наличии жиров немолочного происхождения и реализации молокосодержащей продукции под видом молочной;

- стимулирование потребления молока и молокопродуктов через программу внутренней продовольственной помощи и развитие инфраструктуры системы социального питания; программы стимулирования потребления молока и 
молочных продуктов (по аналогии с программой Союзмолоко «Три молочных продукта в день»).

Перспектива мировой молочной промышленности является привлекательной для компаний, которые способны удовлетворить как увеличивающийся спрос на развивающихся рынках, так и потребность в новых продуктах среди потребителей в своих развитых регионах.
Глобализация со значительным влиянием на внутреннюю и международную торговлю в молочной промышленности ускорится в ближайшие годы, поскольку большая часть потребителей стремится включить молочные изделия в свой ежедневный рацион с целью укрепить здоровье качественными и доступными продуктами.

\section{Библиографический список}

1. Молочная отрасль-2017: справочник / сост.: А.С. Белов, А.А. Воронин, М.Э. Жебит [и др.] Москва. 2017.380 с.

2. Московская область: статистический сборник / Территориальный орган Федеральной службы государственной статистики по Московской области, 2017. 52 с.

3. Майоров А.А. Анализ современных тенденций в производстве молочных продуктов / Майоров А.А., Сурай Н.М. // Сбор: Аграрная наука сельскому хозяйству сборник статей: в 3 книгах. Барнаул. 2016. С. 254-258.

4. Сурай Н.M. Анализ потребления молока и молочных продуктов в России и Московской области / Сурай Н.M., Неверов П.А., Жукова Н.В. // Модернизация экономических систем: взгляд в будущее (MESLF-2017) Сборник научных трудов Международной научно-практической конференции. Под редакцией П.А. Неверова, Б.А. Аманжоловой. Прага. 2017. С. 79-84.

5. Сурай Н.М. Маркетинговый анализ регионального рынка сыра / Сурай Н.М., Стерликов Ф.Ф., Майоров А.А. // Экономические науки. 2017. № 149. С. 64-69.

6. Официальный сайт Территориального органа Федеральной службы государственной статистики по Московской области www/msko.gks.ru 